\title{
Vitamin D and bone health in early life
}

\author{
Christian Mølgaard* and Kim Fleischer Michaelsen \\ Department of Human Nutrition, LMC Centre for Advanced Food Studies, The Royal Veterinary and Agricultural University, \\ Rolighedsvej 30, DK-1958 Frederiksberg C, Denmark
}

\begin{abstract}
Prolonged vitamin D deficiency resulting in rickets is seen mainly during rapid growth. A distinct age distribution has been observed in the Copenhagen area where all registered hospital cases of rickets were either infants and toddlers or adolescents from immigrant families. Growth retardation was only present in the infant and toddler group. A state of deficiency occurs months before rickets is obvious on physical examination. Growth failure, lethargy and irritability may be early signs of vitamin D deficiency. Mothers with low vitamin D status give birth to children with low vitamin D status and increased risk of rickets. Reports showing increasing rates of rickets due to insufficient sunlight exposure and inadequate vitamin D intake are cause for serious concern. Many countries (including the USA from 2003) recommend vitamin D supplementation during infancy to avoid rickets resulting from the low vitamin D content of human milk. Without fortification only certain foods such as fatty fish contain more than low amounts of vitamin D, and many children will depend entirely on sun exposure to obtain sufficient vitamin D. The skin has a high capacity to synthesize vitamin $\mathrm{D}$, but if sun exposure is low vitamin $\mathrm{D}$ production is insufficient, especially in dark-skinned infants. The use of serum 25 -hydroxyvitamin D to evaluate vitamin D status before development of rickets would be helpful; however, there is no agreement on cut-off levels for deficiency and insufficiency. Furthermore, it is not known how marginal vitamin D insufficiency affects children's bones in the long term.
\end{abstract}

\section{Vitamin D: Bone: Early life}

Vitamin D is the generic name for a group of closely-related seco-steroids with a biological effect and activity similar to that of cholecalciferol (also termed vitamin $\mathrm{D}_{3}$ ) of animal or human origin (van den Berg, 1997). The closely-related ergocalciferol (also termed vitamin $\mathrm{D}_{2}$ ) is formed from plant ergosterol. Severe prolonged vitamin D deficiency during growth will result in rickets.

\section{History of rickets}

Rickets has been known for at least 2000 years. In approximately 130 AD Soranus was aware of this disease affecting children in smoky Roman cities (Baxter-Jones et al. 2003). However, the disease was not considered a major problem until the industrialization of Northern Europe in the 17th century when the incidence of rickets became very high (Holick, 1999). It was also in the 17 th century that Whistler and Glisson presented the classical description of rickets, and the relationship between rickets and socio-economic conditions became evident, for example, in England. In the 18th century Scottish fishermen already knew the value of cod oil in relation to rickets and in 1822 Sniadecki observed that children living in Warsaw had a higher incidence of rickets than children living in rural areas outside Warsaw. Based on this observation he recommended exposure to sunlight as a means of curing this disease (Holick, 1999). Palm, 70 years later, published a survey that reached the same conclusion (Holick, 1999). The understanding of the relationship with vitamin $\mathrm{D}, \mathrm{Ca}$ and $\mathrm{P}$ was not resolved until the 1920s (Goel \& Arneil, 1985). Despite these observations rickets was very prevalent in infants and toddlers in the first half of the 20th century in both the USA and Europe. In the years after the Second World War approximately $4 \%$ of all infants in Copenhagen developed rickets (Flensborg \& Thandrup, 1953), and at the present time rickets is again a growing problem in many industrialized countries, mainly because an increasing number of immigrants are moving to colder climates with less sunshine (Kreiter et al. 2000; Shaw \& Pal, 2002; Pedersen et al. 2003). 


\section{Vitamin D metabolism and function}

Man obtains vitamin D from two main sources, sun exposure and vitamin D-containing foods. The importance of one source depends on the availability of the other source. The skin contains the cholesterol precursor 7-hydrocholesterol. In response to sun exposure 7-hydroxycholesterol absorbs u.v.B light of wavelengths $290-315 \mathrm{~nm}$. The energy uptake results in a bond cleavage and precholecalciferol is formed. The skin temperature induces a thermal isomerization of precholecalciferol resulting in the formation of cholecalciferol, which is transported immediately to the liver in the blood bound to vitamin D-binding protein (Holick, 1999). Foods may contain animal-derived cholecalciferol or plantderived ergocalciferol. Plants and yeast synthesize ergocalciferol from ergosterol in response to sunlight by a process similar to the synthesis of cholecalciferol from 7-dehydrocholesterol in animals and man. Supplements may contain either cholecalciferol or ergocalciferol. The absorption of the fat-soluble vitamin D is dependent on bile salts and the lymphatic transport system. After synthesis in the skin or absorption from food, cholecalciferol and ergocalciferol undergo similar metabolism in the liver and subsequently in the kidneys (Fraser, 1995). Vitamin D undergoes 25hydroxylation in the liver and in the human circulation 25-hydroxyvitamin D (25OHD) has a half-life of 3-4 weeks. It is considered to be the best biomarker for the accumulated effect of dietary vitamin D and vitamin D produced in response to sun exposure, and thereby the best indicator of vitamin D status (van der Wielen et al. 1995; Utiger, 1998). The most biologically-active form of vitamin $\mathrm{D}$ is 1,25dihydroxyvitamin $\mathrm{D}\left(1,25(\mathrm{OH})_{2} \mathrm{D}\right)$, which is synthesized from $25 \mathrm{OHD}$ by $1 \alpha$-hydroxylation in the proximal convoluted tubule of the kidneys; extra-renal synthesis may also take place (Fraser, 1995; Prentice, 2003). This synthesis is under strict control of calciotropic hormones such as parathyroid hormone. The most important function of $1,25(\mathrm{OH})_{2} \mathrm{D}$ is stimulation of active $\mathrm{Ca}$ absorption in the intestines. If concentrations of serum $\mathrm{Ca}$ and serum phosphate are too low there will be reduced mineralization of new bone matrix (osteoid) produced by the osteoblast. Unmineralized osteoid results in low mineral:bone matrix (Department of Health, 1998), a condition characteristic of vitamin D deficiency in both childhood and adulthood. Normally, cholecalciferol and ergocalciferol are considered to have the same biological potency in the human body (van den Berg, 1997; Holick, 2002). However, this concept was questioned in a study in which there was a lower increase in serum 25OHD after supplementation with vitamin ergocalciferol than after supplementation with cholecalciferol (Trang et al. 1998).

\section{Sunlight exposure}

It is very difficult to establish an adequate level of sun exposure. If sun exposure is sufficient there is no requirement for vitamin $\mathrm{D}$ from food, and if the diet has a high vitamin $\mathrm{D}$ content there is no need for sun exposure. Defining adequate sun exposure is therefore dependent on the amount of vitamin D consumed in the diet. Decreased exposure to sunlight of the appropriate wavelength occurs during winter in countries in the higher and lower latitudes, because the sun's maximum angle is very oblique and the longer passage through the atmosphere decreases the extent of wavelengths that stimulate vitamin D synthesis. Seasonal variation in 250HD is well known (Lund \& Sørensen, 1979); for example, in Copenhagen (latitude $56^{\circ} \mathrm{NE}$ ) exposure to sunlight during the months from October to March results in negligible production of vitamin $\mathrm{D}$. Vitamin D production may also be reduced in sunny areas because of cloud cover or air pollution, a serious problem in many big cities. Agarwal et al. (2002) compared a group of 9-24-month-old children living in an area of Delhi, India that had high levels of atmospheric pollution with a comparable age-matched group of children living in an area of Delhi that had less pollution. Mean serum 250HD levels were $12 \cdot 4$ and $27 \cdot 1 \mathrm{ng} / \mathrm{ml}(P<0 \cdot 001)$ respectively for the two areas. This situation is similar to the situation in many European cities 50-100 years ago (Flensborg \& Thandrup, 1953; Holick, 1999). Agarwal et al. (2002) suggest that children living in an area with high air pollution should be offered vitamin D supplementation to prevent development of vitamin D-deficiency rickets. Lifestyles or a cultural practice associated with a reduction in time spent outdoors or an increase in the body surface area covered with clothing may also reduce production of vitamin $\mathrm{D}$ in the skin (Pedersen et al. 2003). Increased skin pigmentation is known to considerably reduce the capacity of the skin to produce vitamin D (Clemens et al. 1982). Another important factor in many countries is the use of sunscreens for protection from skin cancer (Etzel et al. 1999). Use of sunscreens with protection factor 15 reduces the production of cholecalciferol by $99.5 \%$. However, the skin has a very high capacity to produce vitamin D. Exposure to sunlight that causes minimum erythema of the skin (one minimal erythemal dose) of children and adults wearing a bathing suit is estimated to be equal to fifty times the recommendation of $5 \mu \mathrm{g}$ (Holick, 2002). Exposure of one minimal erythemal dose of $6 \%$ of the body is equal to an intake of $15-25 \mu \mathrm{g}$ cholecalciferol. Thus, there is no need for prolonged periods of sunbathing since the production of precholecalciferol occurs immediately upon exposure to sunlight (Holick, 2002). In children slight tanning is a good indicator that they are making enough cholecalciferol.

\section{Vitamin D-containing foods}

Only a limited number of food products contain major amounts of vitamin D (van den Berg, 1997), which is the reason why both children and adults avoiding sun exposure are at risk of developing vitamin D deficiency. Flesh from oily fish such as salmon and mackerel contains high but variable amounts of vitamin D. Eating oily fish three to four times weekly is usually adequate to meet the vitamin D requirement in children (Holick, 2002). Cod-liver oil and oil from other fish are very good sources of vitamin D. Other food items such as meat may contain some 25OHD. As $25 \mathrm{OHD}$ is more water soluble than vitamin $\mathrm{D}$ it is at least partly absorbed via the portal venous system and is therefore less dependent on bile salts (van den Berg, 1997). In some countries a few foods are fortified with vitamin D. These fortified foods are most often milk products or margarine, 
but cereals and some breads are also fortified. Unlike human milk, formula milk normally contains a relatively high amount of vitamin D $(10 \mu \mathrm{g} / \mathrm{l})$. Absorption from vitamin D supplements has been estimated to vary between 55 and 99 $\%$ in adults when given in oil or with fat that stimulates release of bile salts. Absorption from dietary sources is probably lower (van den Berg, 1997).

\section{Fetus}

The fetus is dependent on maternal status and the supply through the placenta for both Ca and vitamin D. Vitamin D is mainly transported through the placenta as 25OHD. During the third trimester there is an increase in the active form of vitamin $\mathrm{D}, 1,25(\mathrm{OH})_{2} \mathrm{D}$, in the mother (Department of Health, 1998). The placenta synthesizes $1,25(\mathrm{OH})_{2} \mathrm{D}$ from $25 \mathrm{OHD}$ for both the mother and the fetus. In the fetus $1,25(\mathrm{OH})_{2} \mathrm{D}$ is also synthesized in the kidneys. The umbilical cord 25OHD level is positively correlated $(r 0 \cdot 81$, $P<0.0001)$ with the plasma 250HD level in the mother (Zeghoud et al. 1997), but the level is lower in the cord than in the mother (Nishimura et al. 2003). One study has shown that infants born during summer have a lower bone mineral content, higher serum osteocalcin and higher $1,25(\mathrm{OH})_{2} \mathrm{D}$ than infants born during winter (Namgung et al. 1994). The authors suggest that vitamin D status during early pregnancy is of particular importance for the newborn's bone mineral content (Namgung et al. 1994). A small study comparing vitamin $\mathrm{D}$ status in newborns from mothers who underwent long-term hospitalization during pregnancy and mothers with normal pregnancy found significantly lower serum 25OHD in the hospitalized mothers compared with control mothers $(P<0 \cdot 01)$, but no significant difference between the cord 25OHD in the two groups (Nishimura et al. 2003). However, cord 250HD relative to maternal 250HD was higher in the hospitalized group than in the control group $(82.1 \% v .60 \cdot 3 \%)$, which may indicate a higher placental transfer in the group with the lower 25OHD. Congenital rickets is related to maternal vitamin $\mathrm{D}$ deficiency during pregnancy (Specker, 1994; Anatoliotaki et al. 2003). Poor maternal vitamin D status may adversely affect foetal growth, bone ossification, tooth enamel formation and neonatal Ca homeostasis (Specker, 1994). These studies underline the importance for the newborn of the mother's vitamin $\mathrm{D}$ status during pregnancy. The fight against rickets has to start with the pregnant women. In a recent review Ann Prentice (2003) concluded that supplementation of pregnant women at risk of vitamin $\mathrm{D}$ deficiency would reduce the risk of rickets and other problems of $\mathrm{Ca}$ handling in the newborn and might promote infant growth. Mothers at risk of vitamin D deficiency during pregnancy will include dark-skinned women with low vitamin D intake from both sunny (Anatoliotaki et al. 2003; Dawodu et al. 2003) and less sunny countries (Henriksen et al. 1995; Shaw \& Pal, 2002) who avoid sun exposure.

\section{Infants and toddlers}

Neonates born of mothers with low 250HD levels will have a poor vitamin $\mathrm{D}$ status from the start and will be at increased risk of developing rickets (Markestad, 1983).
Most of the vitamin D activity in human milk is in the form of 25OHD. The relative amounts of ergocalciferol and cholecalciferol will depend on the mother's dietary intake and extent of sun exposure. Human breast milk normally contains only small amounts of vitamin D metabolites, including 25OHD (Food and Nutrition Board/Institute of Medicine, 1997), and children who are breast-fed and do not receive vitamin D supplementation or adequate exposure to sunlight are at high risk of developing vitamin D deficiency or manifesting rickets (Kreiter et al. 2000; Dawodu et al. 2003). The 25OHD content of human breast milk is influenced by maternal vitamin D status and dietary vitamin $\mathrm{D}$ intake, but there is no correlation between the level in breast milk and plasma 25OHD status in breast-fed infants except when the mother consumes high doses of vitamin D supplements (Department of Health, 1998). Comparison of vitamin D content of milk from white and black women in the same society has shown higher levels in milk from white women $(1.58 \mu \mathrm{g} / 1$ v. $0.98 \mu \mathrm{g} / \mathrm{l}$; Specker et al. 1985). This finding was explained by the higher vitamin $\mathrm{D}$ intake of white women compared with black women, and probably also a higher skin production in white women. There is also a seasonal variation in human milk vitamin $\mathrm{D}$ concentration. In Finland vitamin D activity in milk from unsupplemented women was higher in September $(3 \cdot 1 \mu \mathrm{g} / \mathrm{l})$ compared with February $(0 \cdot 35 \mu \mathrm{g} / \mathrm{l}$; Ala Houhala et al. 1988b). In the same study milk from supplemented women $(25 \mu \mathrm{g}$ vitamin $\mathrm{D} / \mathrm{d})$ had a higher vitamin $\mathrm{D}$ activity compared with milk from unsupplemented women $(0 \cdot 83 \mu \mathrm{g} / 1$ v. 0.35 $\mu \mathrm{g} / \mathrm{l}$; Ala Houhala et al. 1988b). Many years ago it was shown that intake of large quantities of fish liver oil could increase the vitamin D content of human milk (Polskin et al. 1945). However, if the infant were to be protected through human milk alone the mother's intake would have to be so high that there would be a risk of adverse effects in the mother (Ala Houhala et al. 1986). Thus, the breast-fed infant needs either sun exposure or supplementation to avoid vitamin D deficiency and rickets (Kreiter et al. 2000; Dawodu et al. 2003). In most countries there are recommendations for vitamin D supplementation during infancy in order to avoid rickets in breast-fed children (Michaelsen et al. 2000); doses of $5-10 \mu \mathrm{g} / \mathrm{d}$ are usually recommended (Food and Nutrition Board/Institute of Medicine, 1997; Department of Health, 1998; Michaelsen et al. 2000). As cases of rickets continue to be reported in the USA (Kreiter et al. 2000), the US National Academy of Sciences has recently recommended that all infants, including those exclusively breast-fed, have a minimum intake of $5 \mu \mathrm{g}$ vitamin D (Gartner \& Greer, 2003).

Rickets, except the congenital type, typically develops during the early months of life. Growth failure, lethargy and irritability are often early signs, followed by more detectable clinical changes such as craniotabes, costochondral beading, swelling of the distal ends of long bones (wrists and ankles) and bowing of the legs (Pedersen et al. 2003). Severe cases may present with spasm and hypocalcaemic seizures (Ahmed et al. 1995). If rickets is not treated prolonged vitamin $\mathrm{D}$ deficiency may lead to permanent dwarfing, gross bowing of the legs and a distorted pelvis that may give severe obstetric complications later for the girls. Providing all children with vitamin D supplements of 5-10 $\mu \mathrm{g} / \mathrm{d}$ during 
infancy should prevent the development of nutritional rickets during the first year of life (Gartner \& Greer, 2003), except in cases of very low $\mathrm{Ca}$ intake (Okonofua et al. 1991). Regulations in most industrialized countries require that infant formula milk is fortified with vitamin $\mathrm{D}$, usually $1-2.5 \mu \mathrm{g} / 420 \mathrm{~kJ}(100 \mathrm{kcal})$, equivalent to $10 \mu \mathrm{g} / \mathrm{l}$ in a standard formula with $1.5 \mu \mathrm{g} / 420 \mathrm{~kJ}$ (100 kcal) (Gartner \& Greer, 2003).

Children who have received sufficient vitamin D during the first 4-8 months and thereafter an insufficient supply may develop signs of vitamin D deficiency at the age of 1-3 years, with stunting of growth, gross bowing of the legs, muscle weakness, walking problems and deformation of the pelvis. Despite severe leg deformations, healing of these skeletal deformations may still occur with the correct treatment with vitamin D (Biser-Rohrbaugh \& HadleyMiller, 2001).

\section{Puberty}

Rickets is seen mainly in periods of rapid growth and most often in the first years of life. However, late rickets or adolescent rickets occurring during the pubertal growth spurt is also well documented in both sunny (Narchi et al. 2001) and less sunny countries (Pedersen et al. 2003). In accordance with this finding, a distinct age distribution has been observed in the Copenhagen area (Pedersen et al. 2003), where all registered hospital cases of nutritional rickets were either infant and toddler or adolescent patients, mainly girls. Growth retardation was only present in the infant and toddler group. In late rickets a waddling gait, lower limb and back pain, bowing of the legs and muscle weakness are common symptoms (Pedersen et al. 2003). Hypocalcaemic tetany is also common (Narchi et al. 2001). Skeleton deformation is often permanent after late rickets despite corrective treatment. Adolescent rickets is most often seen in females who wear veils for religious reasons (Pedersen et al. 2003). In these cases sun exposure is inadequate, and these girls are totally dependent on food sources of vitamin D.

\section{Prevention}

It is easy to prevent rickets in all age-groups, and prevention should be given high priority. If sun exposure and vitamin D intake from the habitual diet are not sufficient, supplementation should be recommended (Gartner \& Greer, 2003). Thus, supplementation is recommended for most breast-fed infants worldwide and for many immigrant children (and adults) in Western countries (Shaw \& Pal, 2002; Pedersen et al. 2003), but also for girls and women in sunny countries in which wearing a veil is obligatory for religious reasons (Narchi et al. 2001). Children from families with special food customs, such as macrobiotic diets, may also be at particular risk (Dagnelie et al. 1990). If it is not practical to give daily supplements, the provision of a high single dose of $3.75 \mathrm{mg}$ vitamin D to 5-11-year-old children at the beginning of autumn has been shown to maintain appropriate vitamin D status during winter without inducing hypercalcaemia or hypercalcuria (Oliveri et al. 1996).

However, well-designed randomized blinded intervention studies are needed in order to establish the vitamin $\mathrm{D}$ doses required in order to prevent bone problems in different age-groups.

\section{Evaluation of vitmin D status}

In order to prevent the development of severe vitamin D deficiency, biochemical markers of vitamin D status could be relevant for use in screening. The 25OHD levels reflect the body content of vitamin D. In patients with vitamin D deficiency the 25OHD level is decreased and levels of parathyroid hormone and alkaline phosphatase are often elevated (Pedersen et al. 2003). However, there is no international consensus on cut-off levels of 25OHD for vitamin $\mathrm{D}$ deficiency and insufficiency in children or adults. As in adults, an inverse relationship between parathyroid hormone and 25OHD has been found in infants and adolescents (Zeghoud et al. 1997; Guillemant et al. 1999). One proposal for the definition of a sufficient 25OHD level is the level of $25 \mathrm{OHD}$ in a population in which parathyroid hormone has reached a plateau. In a French study of male adolescents this level was as high as $83 \mathrm{nmol} / 1$ (Guillemant et al. 1999). However, there is no consensus on how to define optimal vitamin D status. Another approach would be to measure the effect of additional vitamin $\mathrm{D}$ on bone accretion and establish the level of 25OHD above which additional vitamin D had no further effect on bone accretion. In a double-blinded intervention study from Finland supplementation with $10 \mu \mathrm{g}$ ergocalciferol five to seven times weekly for 1 year had no effect on height or mineral accretion in the distal radius when compared with a placebo (Ala Houhala et al. 1988a). The 25OHD level at baseline in January-February was approximately $19 \mathrm{ng} / \mathrm{ml}(50 \mathrm{nmol} / \mathrm{l}$; Ala Houhala et al. 1988a). In a 3-year longitudinal study of Finnish girls aged 9-15 years Lehtonen-Veromaa et al. (2002) found that baseline 25OHD was positively correlated with unadjusted 3-year change in bone mineral density at the lumbar spine $(r 0.35, P<0.001)$ and femoral neck $(r 0.32$, $P<0.001)$ in all participants, and in the group with advanced sexual maturation at baseline there was a significant difference $(4 \% ; P=0.01$ for trend) between bone accretion in lumbar spine in girls with severe hypovitaminosis D $(25 \mathrm{OHD}<20 \mathrm{nmol} / \mathrm{l})$ compared with girls with normal vitamin $\mathrm{D}$ status (defined as 25OHD $>37.5 \mathrm{nmol} / \mathrm{l}$ ). Another study from Finland has shown that in girls aged $9-15$ years 13.4 and $67.7 \%$ respectively had severe hypovitaminosis $(25 \mathrm{OHD}<20 \mathrm{nmol} / \mathrm{l})$ and insufficient vitamin D status $(25 \mathrm{OHD}<37.5 \mathrm{nmol} / \mathrm{l})$ during wintertime. There is no evidence, in terms of lower peak bone mass, to suggest that these levels of vitamin D are likely to be insufficient in the long term. In order to further investigate whether low 25OHD levels affect bone accretion and peak bone mass, more intervention studies are needed. Until their findings have been published it will not be established whether preventive evaluation of vitamin D status by $25 \mathrm{OHD}$ is relevant in infants, children and adolescents. 


\section{Conclusion}

A sufficient vitamin D status in early life is essential for bone health. Supplementation with vitamin D should therefore be recommended for known risk groups for development of rickets, such as breast-fed infants, darkskinned children from both sunny and non-sunny countries who avoid sun exposure, children in areas with severe air pollution and girls who are veiled for religious reasons. However, it is not known whether low vitamin D status without physical signs of insufficiency has any lasting negative effects on bone development in infants, children and adolescents. Until more data on relevant cut-off levels for $25 \mathrm{OHD}$ are available, recommendations for a healthy life that include sun exposure and intake of vitamin D-containing food products should be retained, and in cases of doubt about an individual's vitamin D status supplementations should be recommended to avoid possible negative effects.

\section{References}

Agarwal KS, Mughal MZ, Upadhyay P, Berry JL, Mawer EB \& Puliyel JM (2002) The impact of atmospheric pollution on vitamin D status of infants and toddlers in Delhi India. Archives of Disease in Childhood 87, 111-113.

Ahmed I, Atiq M, Iqbal J, Khurshid M \& Whittaker P (1995) Vitamin D deficiency rickets in breast-fed infants presenting with hypocalcaemic seizures. Acta Paediatrica 84, 941-942.

Ala Houhala M, Koskinen T, Koskinen M \& Visakorpi JK (1988a) Double blind study on the need for vitamin D supplementation in prepubertal children. Acta Paediatrica Scandinavica 77, 89-93.

Ala Houhala M, Koskinen T, Parviainen MT \& Visakorpi JK (1988b) 25-Hydroxyvitamin D and vitamin D in human milk: effects of supplementation and season. American Journal of Clinical Nutrition 48, 1057-1060.

Ala Houhala M, Koskinen T, Terho A, Koivula T \& Visakorpi J (1986) Maternal compared with infant vitamin D supplementation. Archives of Disease in Childhood 61, 1159-1163.

Anatoliotaki M, Tsilimigaki A, Tsekoura T, Schinaki A, Stefanaki S \& Nikolaidou P (2003) Congenital rickets due to maternal vitamin D deficiency in a sunny island of Greece. Acta Paediatrica 92, 389-391.

Baxter-Jones ADG, Mirwald RL, McKay HA \& Bailey DA (2003) A longitudinal analysis of sex differences in bone mineral accrual in healthy 8-19-year-old boys and girls. Annals of Human Biology 30, 160-175.

Biser-Rohrbaugh A \& Hadley-Miller N (2001) Vitamin D deficiency in breast-fed toddlers. Journal of Pediatric Orthopaedics 21, 508-511.

Clemens TL, Adams JS, Henderson SL \& Holick MF (1982) Increased skin pigment reduces the capacity of skin to synthesise vitamin D. Lancet i, 74-76.

Dagnelie PC, Vergote FJ, van Staveren WA, van den Berg H, Dingjan PG \& Hautvast JG (1990) High prevalence of rickets in infants on macrobiotic diets. American Journal of Clinical Nutrition 51, 202-208.

Dawodu A, Agarwal M, Hossain M, Kochiyil J \& Zayed R (2003) Hypovitaminosis D and vitamin D deficiency in exclusively breast-feeding infants and their mothers in summer: A justification for vitamin D supplementation of breast-feeding infants. Journal of Pediatrics 142, 169-173.

Department of Health (1998) Nutrition and Bone Health: With Particular Reference to Calcium and Vitamin D, 1st ed. London: The Stationery Office.
Etzel RA, Balk SJ, Bearer CF, Miller MD, Shannon MW, Shea KM, Falk H, Goldman LR, Miller RW, Rogan W \& Coven B (1999) Ultraviolet light: A hazard to children. Pediatrics 104, 328-333.

Flensborg EW \& Thandrup E (1953) Rickets and tetany in the paediatric departments in Greater Copenhagen 1946-1951. Ugeskrift For Laeger 115, 1237-1244.

Food and Nutrition Board/Institute of Medicine (1997) Vitamin D Dietary Reference Intakes for Calcium, Phosphorus, Magnesium, Vitamin D, and Fluoride, pp. 250-287. Washington, DC: National Academy Press.

Fraser DR (1995) Vitamin D (review). Lancet 345, 104-107.

Gartner LM \& Greer FR (2003) Prevention of rickets and vitamin D deficiency: New guidelines for vitamin D intake. Pediatrics 111, 908-910.

Goel KM \& Arneil GC (1985) Rickets, old and new. In Pediatric Nutrition, pp. 219-244 [GC Arneil and J Metcoff, editors]. London: Butterworths.

Guillemant J, Taupin P, Le HT, Taright N, Allemandou A, Peres G \& Guillemant S (1999) Vitamin D status during puberty in French healthy male adolescents. Osteoporosis International $\mathbf{1 0}$, 222-225.

Henriksen C, Brunvand L, Stoltenberg C, Trygg K, Haug E \& Pedersen JI (1995) Diet and vitamin D status among pregnant Pakistani women in Oslo. European Journal of Clinical Nutrition 49, 211-218.

Holick MF (1999) Vitamin D. In Modern Nutrition in Health and Disease, pp. 329-345 [ME Shils, JA Olson, M Shike and AC Ross, editors]. Baltimore, MD: Williams \& Wilkins.

Holick MF (editor) (2002) Calcium and vitamin D in human health. In Calcium in Childhood, pp. 83-93. Vevey, Switzerland: Nestlé Nutrition.

Kreiter SR, Schwartz RP, Kirkman HN, Charlton PA, Calikoglu AS \& Davenport ML (2000) Nutritional rickets in African American breast-fed infants. Journal of Pediatrics 137, 153-157.

Lehtonen-Veromaa MKM, Mottonen TT, Nuotio IO, Irjala KMA, Leino AE \& Viikari JSA (2002) Vitamin D and attainment of peak bone mass among peripubertal Finnish girls: a 3-y prospective study. American Journal of Clinical Nutrition 76, $1446-1453$.

Lund B \& Sørensen OH (1979) Measurement of 25-hydroxyvitamin $\mathrm{D}$ in serum and its relation to sunshine, age and vitamin D intake in the Danish population. Scandinavian Journal of Clinical and Laboratory Investigation 39, 23-30.

Markestad T (1983) Effect of season and vitamin D supplementation on plasma concentrations of 25 -hydroxyvitamin $\mathrm{D}$ in Norwegian infants. Acta Paediatrica 72, 817-821.

Michaelsen KF, Weaver L, Branca F \& Robertson A (editors) (2000) Vitamins. In Feeding and Nutrition of Infants and Young Children. WHO Regional Publications European Series no. 87, pp. 76-80. Copenhagen, Denmark: WHO European Regional Office.

Namgung R, Tsang RC, Specker BL, Sierra RI \& Ho ML (1994) Low bone mineral content and high serum osteocalcin and 1,25-dihydroxyvitamin $\mathrm{D}$ in summer- versus winter-born newborn infants: an early fetal effect? Journal of Pediatric Gastroenterolgy and Nutrition 19, 220-227.

Narchi H, El Jamil M \& Kulaylat N (2001) Symptomatic rickets in adolescence. Archives of Disease in Childhood 84, 501-503.

Nishimura K, Shima M, Tsugawa N, Matsumoto S, Hirai H, Santo Y, Nakajima S, Iwata M, Takagi T, Kanda Y, Kanzaki T, Okano T \& Ozono K (2003) Long-term hospitalization during pregnancy is a risk factor for vitamin D deficiency in neonates. Journal of Bone and Mineral Metabolism 21, 103-108.

Okonofua F, Gill DS, Alabi ZO, Thomas M, Bell JL \& Dandona P (1991) Rickets in Nigerian children: a consequence of calcium malnutrition. Metabolism 40, 209-213. 
Oliveri B, Cassinelli H, Mautalen C \& Ayala M (1996) Vitamin D prophylaxis in children with a single dose of 150000 IU of vitamin D. European Journal of Clinical Nutrition 50, 807-810.

Pedersen P, Michaelsen KF \& Mølgaard C (2003) Children with nutritional rickets referred to hospitals in Copenhagen during a 10-year period. Acta Paediatrica 92, 87-90.

Polskin LJ, Kramer B \& Sobel AE (1945) Secretion of vitamin D in milks of women fed fish liver oil. Pediatric Research 2, 451-466.

Prentice A (2003) Micronutrients and the bone mineral content of the mother, fetus and newborn. Journal of Nutrition 133, Suppl., 1693S-1699S.

Shaw NJ \& Pal BR (2002) Vitamin D deficiency in UK Asian families: activating a new concern. Archives of Disease in Childhood 86, 147-149.

Specker BL (1994) Do North American women need supplemental vitamin D during pregnancy or lactation? American Journal of Clinical Nutrition 59, Suppl., 484S-490S.
Specker BL, Tsang RC \& Hollis BW (1985) Effect of race and diet on human-milk vitamin D and 25-hydroxyvitamin D. American Journal of Disease in Children 139, 1134-1137.

Trang HM, Cole DEC, Rubin LA, Pierratos A, Siu S \& Vieth R(1998) Evidence that vitamin D-3 increases serum 25-hydroxyvitamin D more efficiently than does vitamin D-2. American Journal of Clinical Nutrition 68, 854-858.

Utiger RD (1998) The need for more vitamin D. New England Journal of Medicine 338, 828-829.

van den Berg H (1997) Bioavailability of vitamin D. European Journal of Clinical Nutrition 51, Suppl., S76-S79.

van der Wielen RPJ, Lüwik MRH, van der Berg $\mathrm{H}$, de Groot LCPGM, Haller J, Moreiras O \& van Staveren WA (1995) Serum vitamin D concentrations among elderly people in Europe. Lancet 346, 207-210.

Zeghoud F, Vervel C, Guillozo H, Walrant-Debray O, Boutignon H \& Garabédian M (1997) Subclinical vitamin D deficiency in neonates: definition and response to vitamin D supplements. American Journal of Clinical Nutrition 65, 771-778. 